2015

Impacts of signal free corridors on the incidence of road traffic accidents in Karachi

Salman Zubair

Jamil H. Kazm

Syed Shahid Ali

Rashid Jooma

Zeeshan Akhtar

Follow this and additional works at: https://ecommons.aku.edu/pakistan_fhs_mc_surg_neurosurg

Part of the Neurology Commons, Neurosurgery Commons, Surgery Commons, and the Trauma Commons 


\title{
Impacts of Signal Free Corridors on the Incidence of Road Traffic Accidents in Karachi
}

\author{
Salman Zubair ${ }^{1, *}$, Jamil H. Kazmi ${ }^{1}$, Syed Shahid Ali ${ }^{1}$, Rashid Jooma ${ }^{2}$ and Zeeshan Akhtar ${ }^{3}$ \\ ${ }^{1}$ Department of Geography, University of Karachi, Karachi -75270, Pakistan \\ ${ }^{2}$ Road Traffic Injury Prevention Center, Karachi, Pakistan \\ ${ }^{3}$ Department of Applied Chemistry, University of Karachi, Karachi, Pakistan
}

\begin{abstract}
Increase in road Traffic Accidents is a global phenomenon and Pakistan is no exception. In Karachi, this problem becomes severe due to rapid growth of population. This menace is ruining the lives of thousands of people and making Karachi a worrisome place to live. Recent road geometrical transitions in the city with insufficient accessories have been reducing the problem of traffic congestion to a limited extent. On the contrary, this has erupted as a problem of Road Traffic Accidents which is reaching out of proportions. Recently, induction of a unique feature named, Signal Free Corridor in Karachi has cost many precious lives. In this paper GIS based analysis has been employed by using buffer technique to document the number of Road Traffic Accidents on four Signal Free Corridors, evaluated for five different years. It was revealed that the minor injury accidents were highest in all four Signal Free Corridors. However, in some cases number of severe and fatal road accident cases showed the emerging trend as well. Four types of road users were identified on these corridors out of which riders/pillion and pedestrians were the most vulnerable to Road Traffic Accidents. There is an emergent need to enforce the vehicle speed rules and regulations that would provide breathing time to traffic as well as reduce the incidents of consistent traffic blockages and rising Road Traffic Accidents.
\end{abstract}

Keywords: Road Traffic Accidents, Signal Free Corridors, Geometrical Advancement, GIS, Buffer Analysis.

\section{INTRODUCTION}

Road Traffic Accidents (RTAs) are an ignored epidemic on the world's roadways. Recently, speedy motorization has influenced the lives of many individuals in particular and societies in general. Deaths due to RTAs are expected to be increase to $83 \%$ in low and middle income countries and to decline by $27 \%$ in high income countries. Generally, it is prognosticated that fatalities would climb to $67 \%$ by 2020 in developing countries if sufficient measures are not taken on time to limit this problem [1]. Erroneous road designs are equally responsible to increase the number of RTA events, where designs are more traffic focused than road users. In Utah (USA), involvement of Trucks in road accidents are highly magnified with the degree of curvature of road design along with the gradient per mile [2]. In Turkey, positive correlation was observed between road geometry designs including the sum of the lengths of the alignment section on the road, with road accident events on highways. The study revealed of higher number of fatal and injury road accidents on increasing length of the road alignment [3]. Likewise, Karachi is amongst the highest road accident conceiving cities of the world [4] which resulted in monetary and life loss to irrecoverable extents [5] with more than thirty percent of these

*Address correspondence to this author at the Department of Geography, University of Karachi, Karachi, Pakistan; Tel: 92-300-2265600;

E-mail: salman_zubair@uok.edu.pk.com,salman_zubair@hotmail.com incidents caused due to geometrical errors in road design [6]. In Karachi, $U$ turns contributed to higher number of fatal and severe injury roads accidents [7]. Traffic congestion is a regular feature on arteries of Karachi especially during rush hours. Furthermore, road geometry is responsible for more than twenty percent of traffic jams in the city [8].

\section{STUDY OBJECTIVES}

The objective of this study is to decipher the impact of recent evolution of four Signal Free Corridors in Karachi on number of RTAs with spatial display.

\section{MATERIAL AND METHOD}

Following are the techniques adopted for the execution of the study:

\section{Study Area: Karachi City}

Karachi lies at the southern boundary of Pakistan at $24^{\circ} 45^{\prime} \mathrm{N}$ to $25^{\circ} 37^{\prime} \mathrm{N}$ and $66^{\circ} 42^{\prime} \mathrm{E}$ to $67^{\circ} 34^{\prime}$ E. Being a coastal city, Karachi is a center of national and international trade for the country and is considered as the financial capital of Pakistan. The author used the Administrative Divisions of Towns as the matrix due to the availability of data and ease of understanding the spatial variation of road accidents in the city. Growing trade activities in the city have inflicted the rapid urbanization which has consequently increased the demand of infrastructure development in the city. 


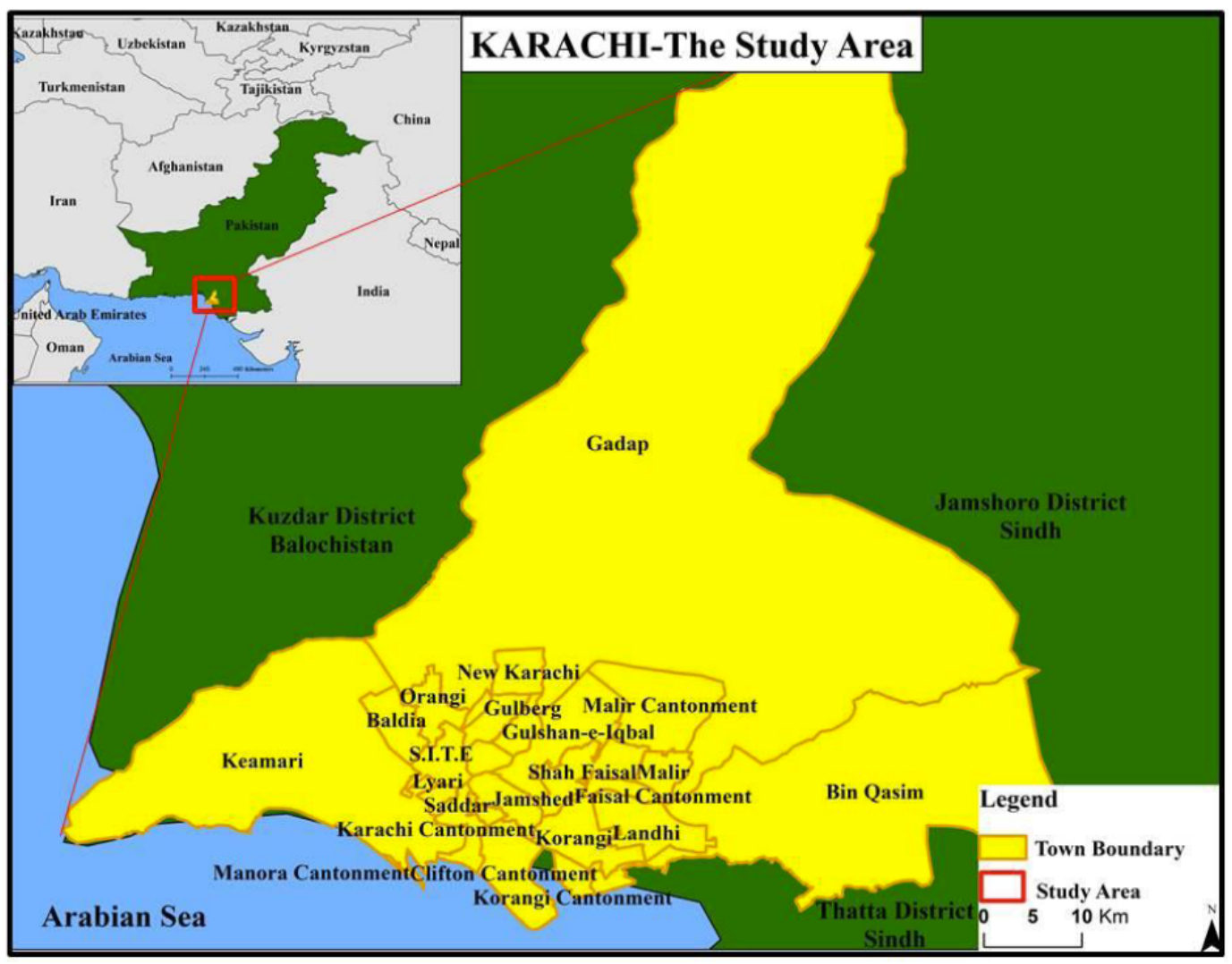

Figure 1: Town Boundaries of Karachi. Source: Author.

Revolutionary infrastructure advancements have been prosecuted in the form of wide and speedy roads, flyovers, pedestrian bridges and under passes, transformation of roundabouts to signals and development of Signal Free Corridors which has ended up increasing number of road traffic related problems in the city.

\section{Spatial Evaluation of Transportation Network in Karachi}

Road network of Karachi grew rapidly to accommodate the ever growing vehicular traffic. The following section sheds light on the different aspects of roads and transportation in the city.

\section{Road Density Analysis}

Transportation network of Karachi is dominated by roads with total length of more than $9,500 \mathrm{~km}$, accommodating more than 3.1 million vehicles. Numbers of vehicles have already jumped-up to $3,127,582$ in 2013 with an annual increase of 338,695. This resulted to dire need of increase of road facilities for road users. The highest road density has been observed in Saddar town, i.e., $4 / \mathrm{Km}$. This town experiences the most heterogeneous economic activities and vehicular traffic. From multistory buildings of head offices to ordinary street hawkers are present here. The least road density is noticed in Gadap town, i.e., $0.1 / \mathrm{Km}$ due to its largest aerial extent. The Town has least developed infrastructure due to the fact that it is farthest from the city center with least population.

\section{Motorization in Karachi}

During the recent years Karachi has been facing a massive increase of vehicles due to easy loan policies by private banks, which has been worsening the traffic conditions in the city, increasing the incidents of traffic jam and RTAs in Karachi. Table $\mathbf{1}$ depicts the enormous increase of vehicles in Karachi during the past few years.

Table 2 depicts that the highest proportion of vehicles relying on roads of Karachi is comprised of cars. In Karachi about $75 \%$ of the inhabitants depend on public transport have only $2.7 \%$ of the total running vehicles. This has accelerated the problem of road accidents because commuters have to travel in horrifying conditions in public transports and public buses have to carry more passengers than their specified capacity. 


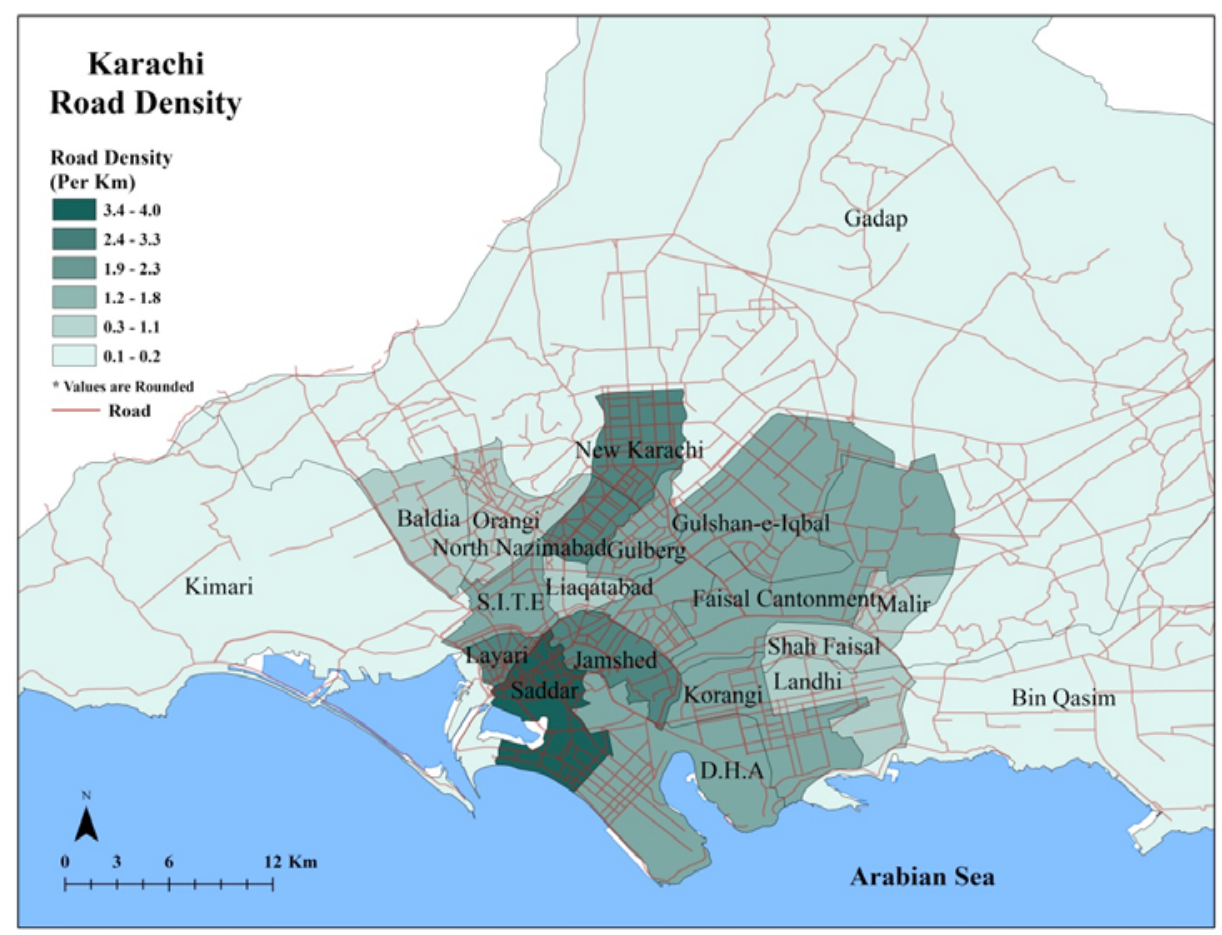

Figure 2: Map showing Road Network and Road Density of different towns of Karachi.

Table 1: Diurnal Increase of Vehicles in Karachi

\begin{tabular}{|c|c|c|c|c|}
\hline \multicolumn{5}{|c|}{ Total Number of Vehicles in Karachi } \\
\hline Year & Registered Vehicles & Annual Increase & Monthly Increase & Daily Increase \\
\hline \hline 2002 & $1,113,917$ & 30,640 & 2,553 & 84 \\
\hline 2003 & $1,177,315$ & 63,398 & 5,283 & 174 \\
\hline 2004 & $1,280,349$ & 102,934 & 8,578 & 282 \\
\hline 2005 & $1,431,994$ & 151,745 & 12,645 & 415 \\
\hline 2006 & $1,610,757$ & $1,78,763$ & 14,897 & 489 \\
\hline 2007 & $1,809,500$ & 198,743 & 16,562 & 545 \\
\hline 2011 & $2,614,859$ & 201,340 & 16,778 & 560 \\
\hline 2012 & $2,788,887$ & 174,028 & 14,502 & 484 \\
\hline 2013 & $3,127,582$ & 338,695 & 28,225 & 941 \\
\hline
\end{tabular}

Source: (Wajid, 2008. and Amir, et al., 2014).

Table 2: Different types of vehicles increased from 2004 till 2011

\begin{tabular}{|c|c|c|c|}
\hline \multicolumn{4}{|c|}{ Comparison of Estimated Total Vehicles in Karachi } \\
\hline Karachi City & $\mathbf{2 0 0 4}$ & $\mathbf{2 0 1 1}$ & Percentage \\
\hline \hline Registered Cars & 1.03 Million & 2.21 Millions & $66.5 \%$ \\
\hline Taxis & 27,233 & 44,011 & $1.3 \%$ \\
\hline Buses & 12,700 & 20,010 & $0.6 \%$ \\
\hline Minivans & 33,200 & 69,135 & $2.1 \%$ \\
\hline Motorcycle & 0.4 million & +1 Million & $30.1 \%$ \\
\hline Total Vehicles & 1.5 Million & 3.32 Million & \\
\hline
\end{tabular}

Source: (Government of Sindh, 2011). 


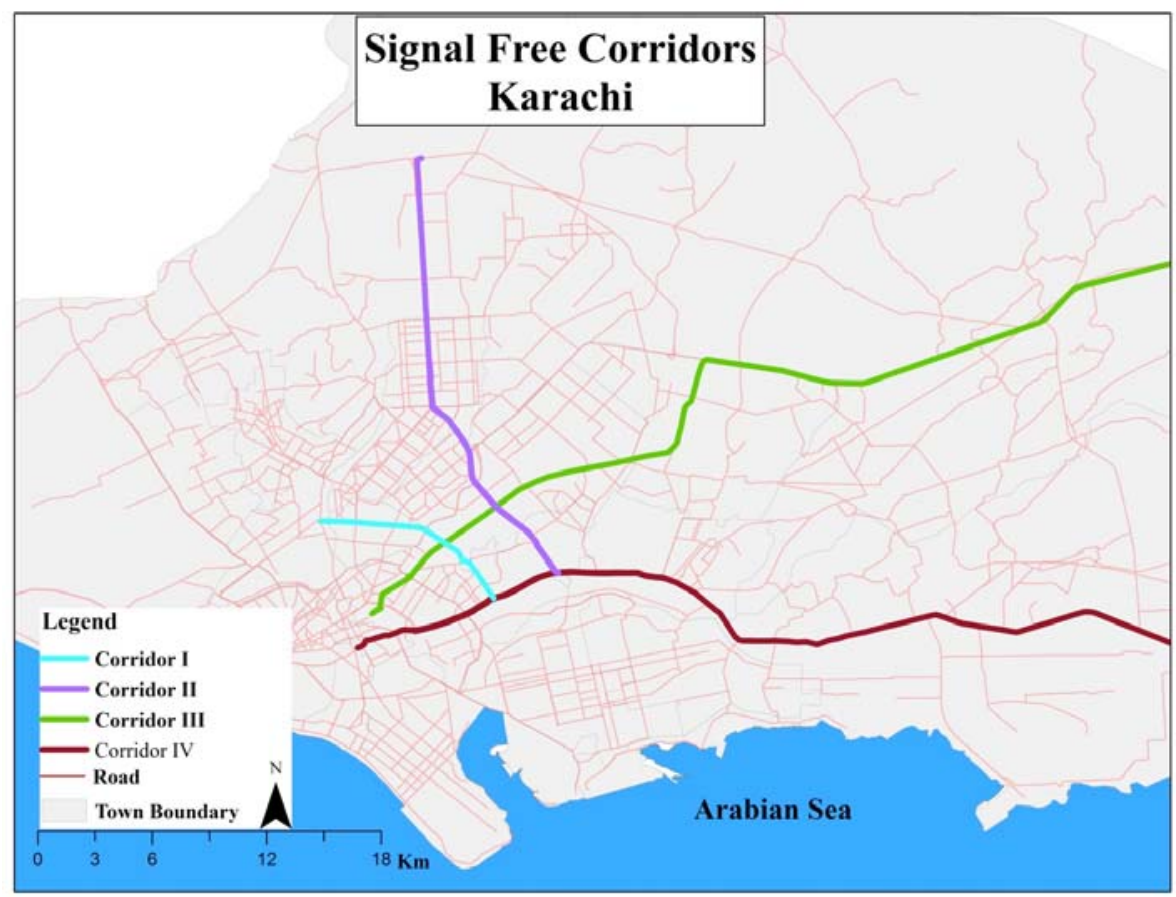

Figure 3: Signal Free Corridors in Karachi.

\section{Appraisal of Road Design Geometry in Karachi}

To facilitate millions of vehicular traffic in the city the road designed geometry had undergone a considerable change over time. Those include increase of road width, construction of flyovers and underpasses, reduction of diameter of roundabouts, transformation of roundabouts to signals and intrusion of signal free corridors that aimed to connect the marginal areas with the core business parts of the city within minimum possible time. These changes have partly been able to reduce the problem of traffic jams but the grey part of these innovations is that, it has increased the incidents of severe and fatal road accidents to an alarming extent.

\section{Spatial Assessment of Signal Free Corridors}

Signal Free Corridors is a recent term introduced theoretically and practically in urban transportation arena of Karachi. To facilitate the fast moving cars and other freight carrying vehicles, signal free corridors were developed with huge capital investments. The following sections throw light on important spatial aspects of four signal free corridors of the city.

\section{Signal Free Corridor I}

A $10.5 \mathrm{Km}$ long first ever Signal Free Corridor was instated on February 09, 2007 by the local government that connected Sharah-e-Faisal with SITE town [9].

\section{Signal Free Corridor II}

A 19-Kilometer long highway type road was inaugurated on October $9^{\text {th }}, 2008$, named Signal Free Corridor II. It took nearly one year in its completion. The corridor connects Shara-e-Faisal with Surjani Round about [10].

\section{Signal Free Corridor III}

A 28-Kilometer long Signal free Corridor III, connecting Karachi Toll Plaza to Saddar Dawa Khana, was inaugurated on August 13, 2009 [11].

\section{Signal Free Corridor IV}

A nearly 28-Kilometer long signal free corridor is planned and in progress in Karachi that will connect Malir to PIDC through Shara-e-Faisal [12].

\section{Spatial Analysis}

Base map of Karachi was prepared and Road network was digitized after geo-referencing the maps of different years, taken from library archive of the Department of Geography, University of Karachi. Road densities were calculated separately in excel sheet, subsequently it was inserted as attribute data in ARC GIS10.1 software. Road densities of different towns were mentioned through choropleth map. Incidence of different road accident events were geo-coded on the 
Google earth with the help of information provided by the victims or their relatives in hospitals, subsequently the most appropriate location were marked with the support of RTIPC officials and NED University along with the students of Department of Geography, University of Karachi. Spatial pattern of road accidents revealed that most of the accident cases were reported from high density road towns of the city. Moreover, road user facilities were marked with the help of Google Earth Imagery.

\section{Buffer Technique}

Point coordinate data of each RTA were plotted on WGS84 coordinate system. A $50 \mathrm{~m}$ buffer was generated along every SFC and then coordinate data of accident were taken out by applying intersect technique. Then, those accidents were further classified as Minor, Severe and Fatal accidents.
Moreover, types of road users involved in those selected RTA were also extracted from the attribute data by applying multiple queries.

Following results were obtained from each signal free corridor.

\section{RESULTS AND DISCUSSION}

\section{Facilities at Signal Free Corridors}

To accommodate the mass movement of free flow of traffic, Signal Free Corridors are equipped with number of architectural facilities, which include Underpasses, $U$ turns, pedestrian bridges and flyovers (Figure 4). These provided facilities having proved to be insufficient for the users, provoke them to violate the traffic laws in form of wrong movement, inappropriate place for road crossing etc.

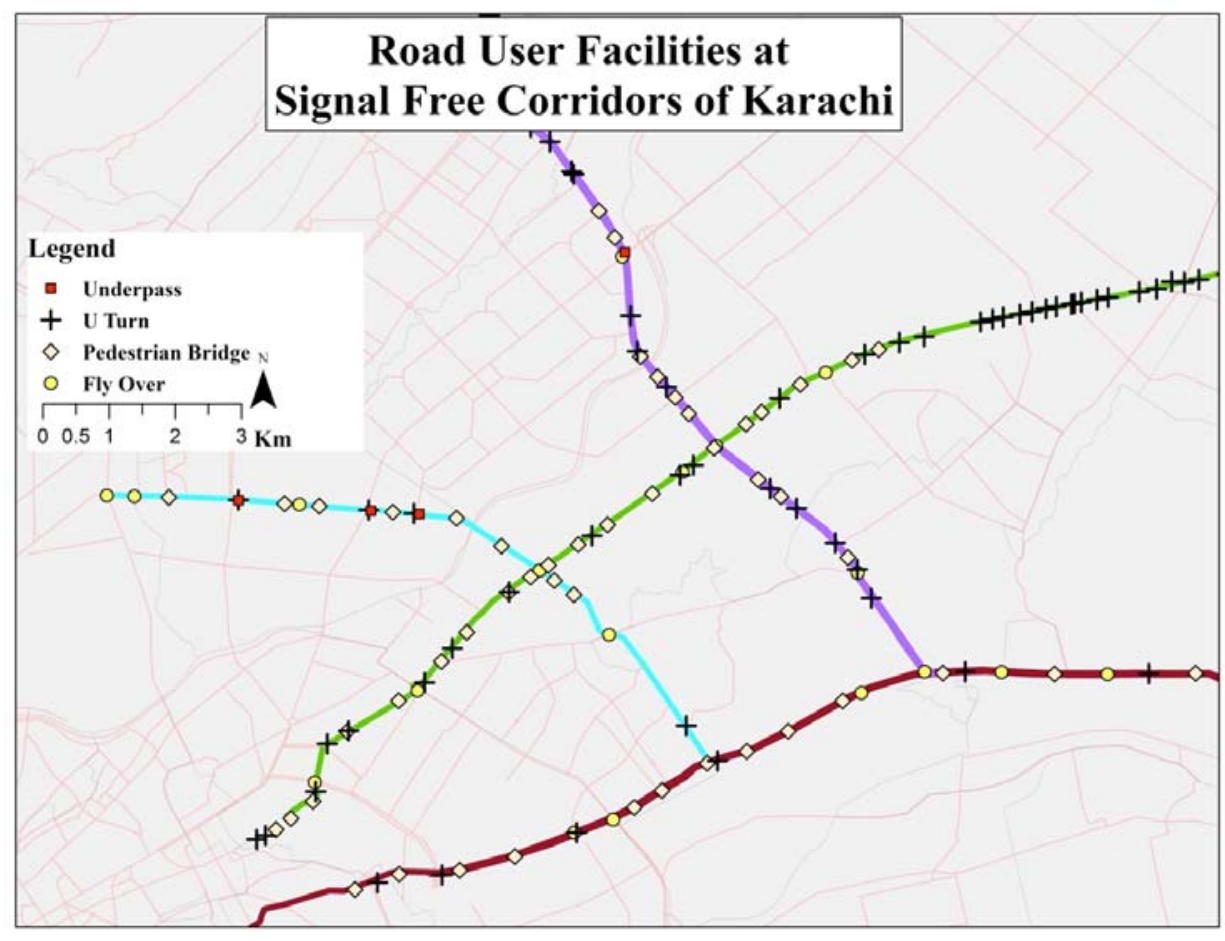

Figure 4: Road User facilities on Signal Free Corridors of Karachi Source: Author.

Table 1: Facilitates at Signal Free Corridors of Karachi

\begin{tabular}{|c|c|c|c|c|c|}
\hline \multicolumn{7}{|c|}{ Number of Facilities at Signal Free Corridors } \\
\hline SFCs & Road Length in Km & Underpass & U-Turn & Pedestrian Bridge & Flyovers \\
\hline \hline Corridor I & 11 & 3 & 4 & 6 & 15 \\
\hline Corridor II & 19 & 1 & 45 & 4 & 19 \\
\hline Corridor III & 28 & - & 39 & 15 & 7 \\
\hline Corridor IV & 28 & - & 9 & 9 \\
\hline
\end{tabular}


Table 4: Average Distance in $\mathrm{Km}$ of Facilities at Signal Free Corridors

\begin{tabular}{|c|c|c|c|c|}
\hline \multicolumn{5}{|c|}{ Average Distance in Km of Facilities at Signal Free Corridors } \\
\hline SFCs & Underpass & U-Turn & Pedestrian Bridge & Flyovers \\
\hline \hline Corridor I & 3.6 & 2.7 & 1.3 & 1.8 \\
\hline Corridor II & 19 & 0.4 & 1.2 & 6.3 \\
\hline Corridor III & - & 0.6 & 1.5 & 4 \\
\hline Corridor IV & - & 0.7 & 1.8 & 3.1 \\
\hline
\end{tabular}

Table 3 depicts that the number of facilities are insufficient for users. Average distance among each $U$ turn is nearly $1.1 \mathrm{Km}$ which provokes bike riders to move wrong way to save fuel. There are many unidentified $U$ turns on these corridors that are more threatening to road users. Pedestrian involvement is also very high at these corridors due to the fact that pedestrians avoid walking over a distance of nearly 1.5 $\mathrm{Km}$ and cross the roads from other than pedestrian bridges. Flyovers are also responsible for high number of road accidents because downslope movement of vehicles increase the velocities that increase the chances of severe accidents.

\section{Consequences of SFC Accessories Pedestrian}

Signal Free Corridors have triggered some serious problems for their users. Pedestrians faced difficulties while crossing the roads because road widths have increased and zebra crossings swapped from pedestrian bridges. These pedestrian bridges are insufficient and placed with average distance of nearly $1.5 \mathrm{Km}$. Another drawback of these bridges is high crime rate due to poor lighting during the night time that provokes people to avoid their use. On an average $U$ turns is present after every $1.1 \mathrm{Km}$. Insufficient number of $U$ turns in these corridors compel vehicle runners to move in the wrong way which results to higher number of head on collisions. Another problem on these corridors is the movement of Chinqhai rickshaw. These small modified motorbike shaped rickshaws with passenger carrying capacity of eight persons, are mostly driven by teen age boys, which increases the vulnerability of road users.

\section{RTAs at Signal Free Corridor I}

Following sections shows the outcome of different severity of road accidents as well as types of road

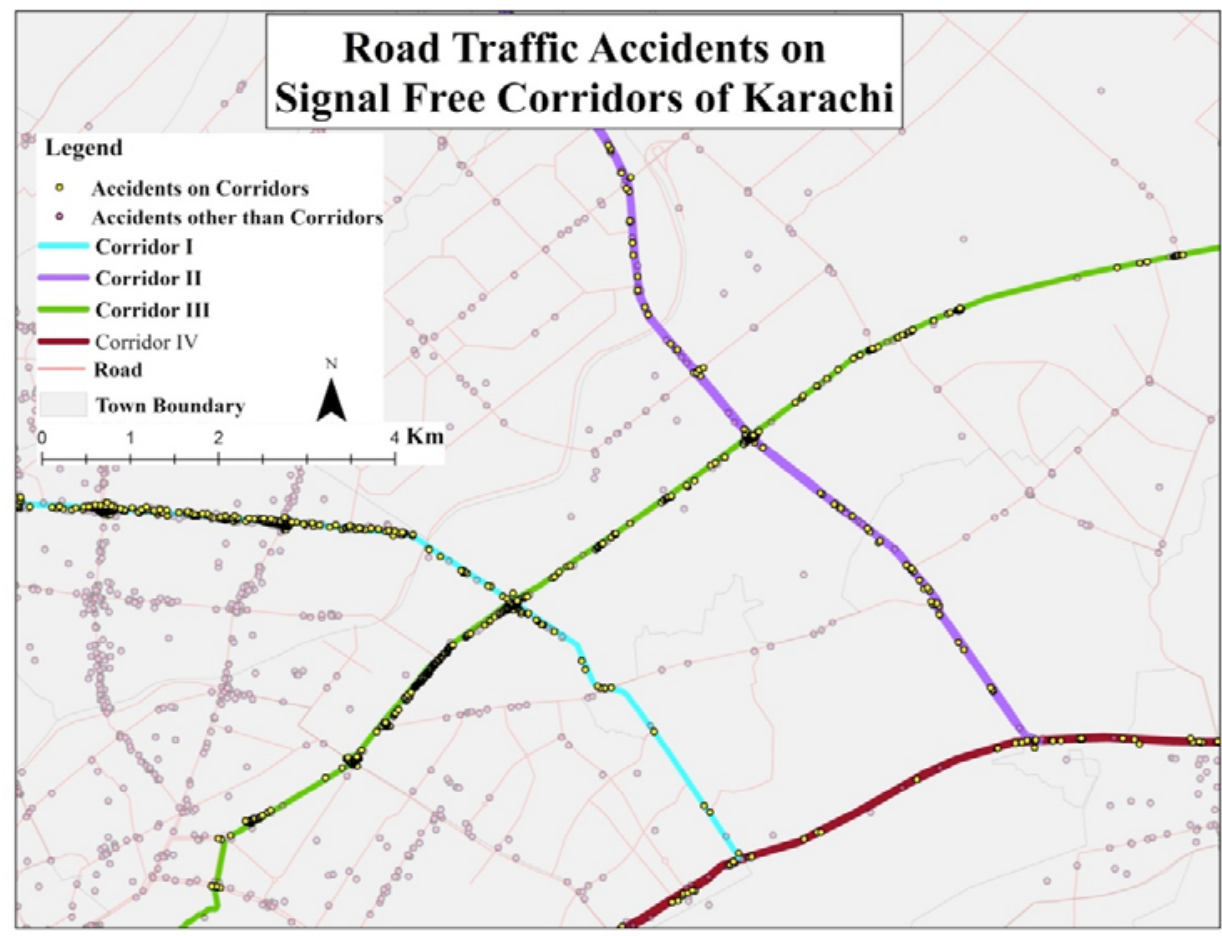

Figure 5: Highlighted Incidence of Road Traffic Accidents on Signal Free Corridors of Karachi. 


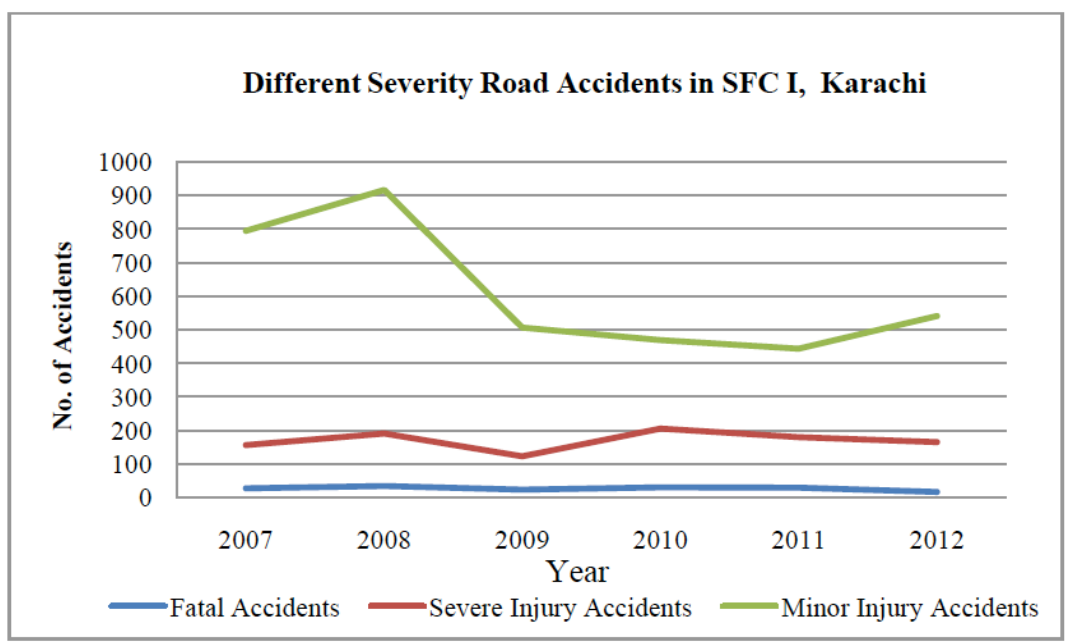

Figure 6: Types of Road Accidents in Corridor I, Karachi.

users involved in four signal free corridors during different time interval.

Minor injury accidents have been reported high in all the corridors of Karachi. In Corridor I, their number jumped from 794 to 916 during 2007 to 2008. This might be due to the fact that people were unaware of the consequences of having fast flowing traffic in the city. It is also assumed that the people with little negligence while on the road became the victims of road accidents. The number of minor injury accidents faced sharp decline to 506 in 2009 however, with the frequent increase of bikes on the road, the steady rise of minor injury accident cases increased to 540 in the year 2012. Concurrently, number of severe injury and fatal road accidents were increased steadily from 156 to 165 (year 2007 until 2012) with peak number recorded in the year 2010 i.e. 205. Whereas, number of fatal cases were dropped from 27 to 17 with peak value of 34 in the year 2008.

Highest number of road users involved in RTAs on SFC 1 were bike pillion riders, though their numbers declined from 815 to 591 during the period 2007 and 2012 and their number were peaked in year 2008 i.e. 958. Drivers were considered as the safest of all road users with least number i.e. 6 in the year 2009 and highest number i.e. 13 in the year 2008. Involvement of passengers in RTA were highest in the year 2008 i.e. 118 victims and least number of passengers were recorded in the year 2011 i.e. 68 . Next most vulnerable category of road users were pedestrians with highest recorded number i.e. 276 in the year 2008 and their least number 167, was recorded in the year 2011.

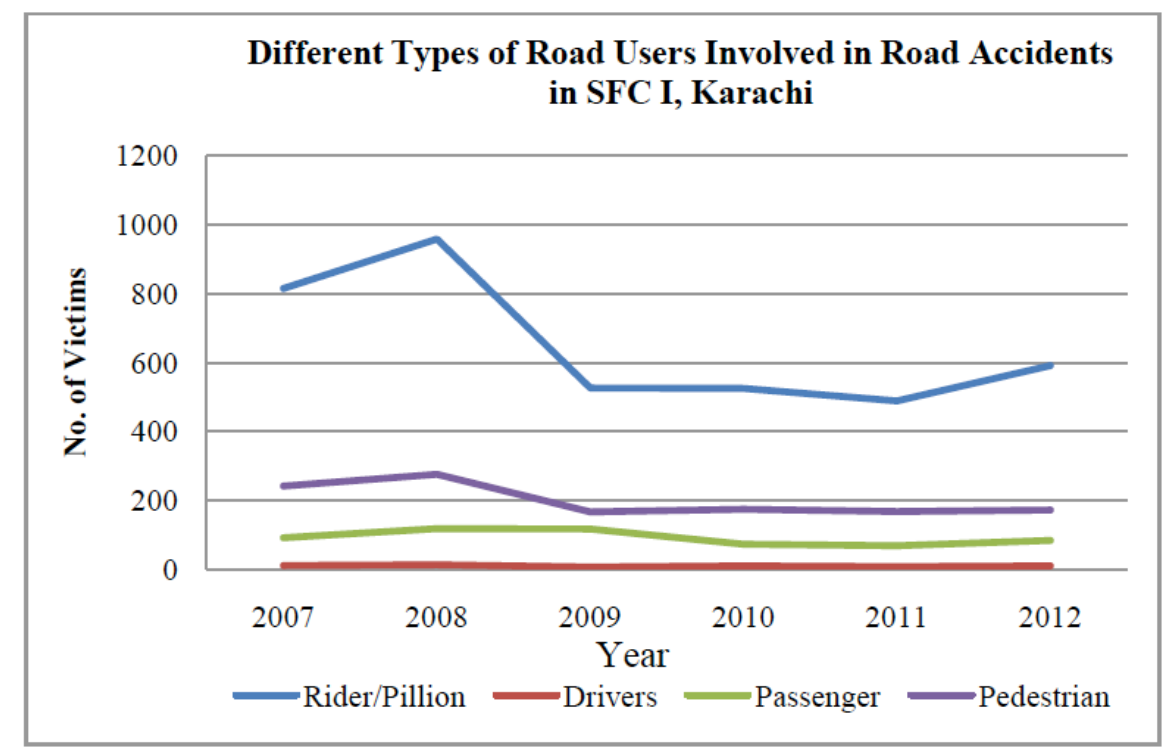

Figure 7: Types of Road users involved in Corridor I in Karachi. 


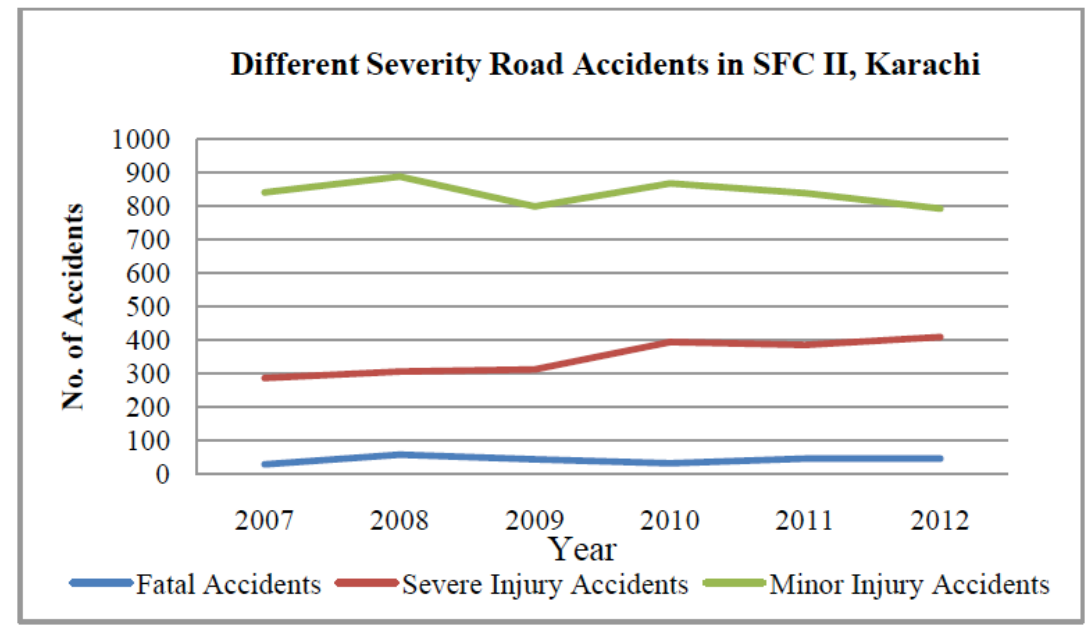

Figure 8: Types of Road Accidents in Corridor II, Karachi.

\section{RTAs at Signal Free Corridor II}

The highest numbers of RTA cases were registered in SFC II, as minor injury accidents i.e. 888 victims were reported in the year 2008. Least number of minor injury victims were reported in 2012 i.e. 792. However, in the same year highest number of severe injury victims and second highest number of fatal injury victims were reported, showing that the high trend was shifted from minor to severe and fatal injury accidents in this corridor during the five year time period.

Bike/pillion riders were highest among all the types of road users involved in RTAs. Least number of such road users who involved were in the year 2009 i.e. 501 . Whereas, highest number of bike/pillion riders who were involved in RTA in 2012, amounted to 1007 . This shows that the bike/pillion riders' involvement in road accidents revealed an increasing trend. Drivers were the least effected victims in this corridor. Involvement of drivers showed a steady trend with least number of 12 in both years of 2010 and 2011 and the highest numbers were revealed in 2009 i.e. 21. Involvement of pedestrians showed an increasing trend between the years 2007 and 2010 subsequently it showed a slightly declining trend of 127 pedestrians in the year 2012 . Passenger involvements have revealed as table trend with least figure106 in the year 2009,and the highest number of passenger involvements, being in the year 2011 to the tune of 147 .

\section{RTAs at Signal Free Corridor III}

Like in other SFCs, this artery showed that the highest number of RTA victims were minor injury victims i.e. 617 in the year 2009. Least number of

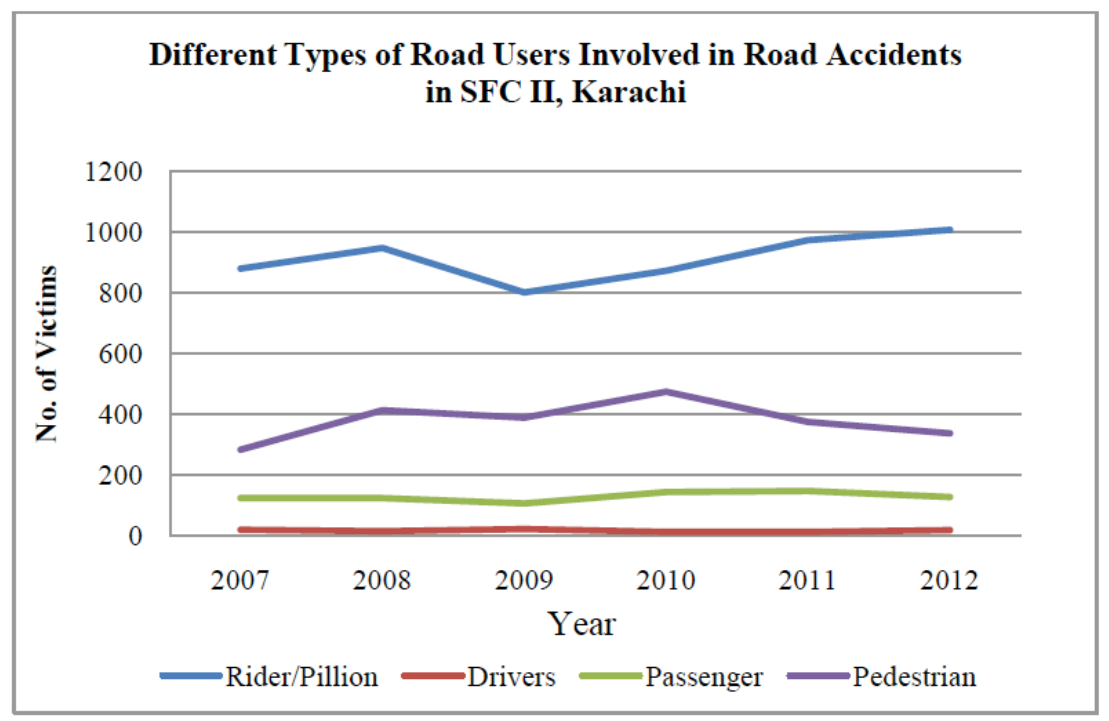

Figure 9: Types of Road users involved in Corridor II in Karachi. 


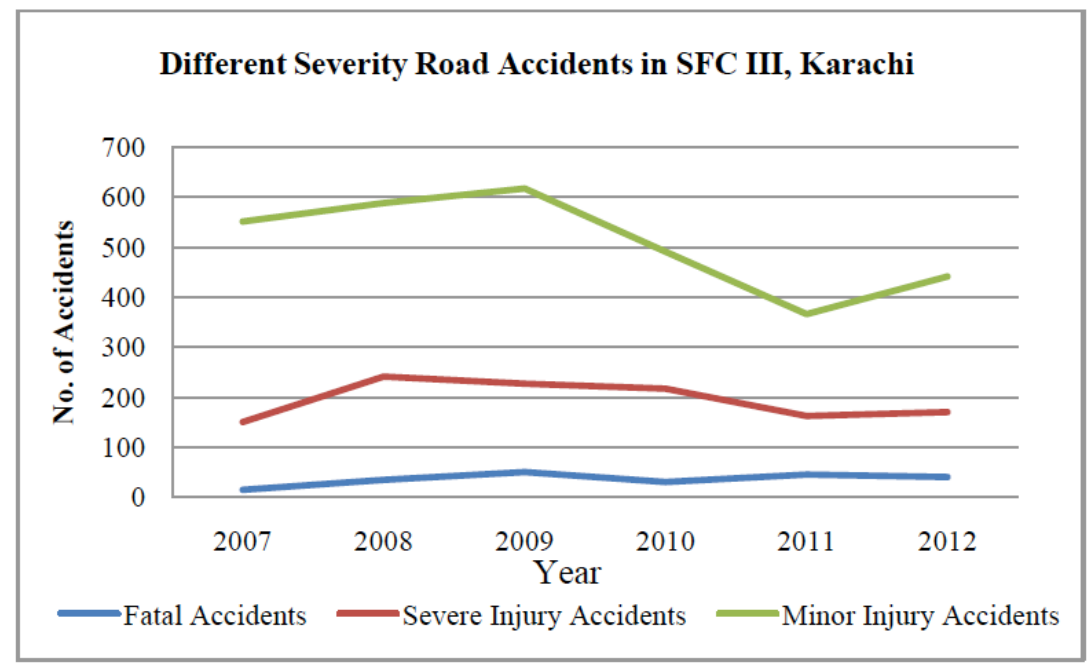

Figure 10: Types of Road Accidents in Corridor III, Karachi.

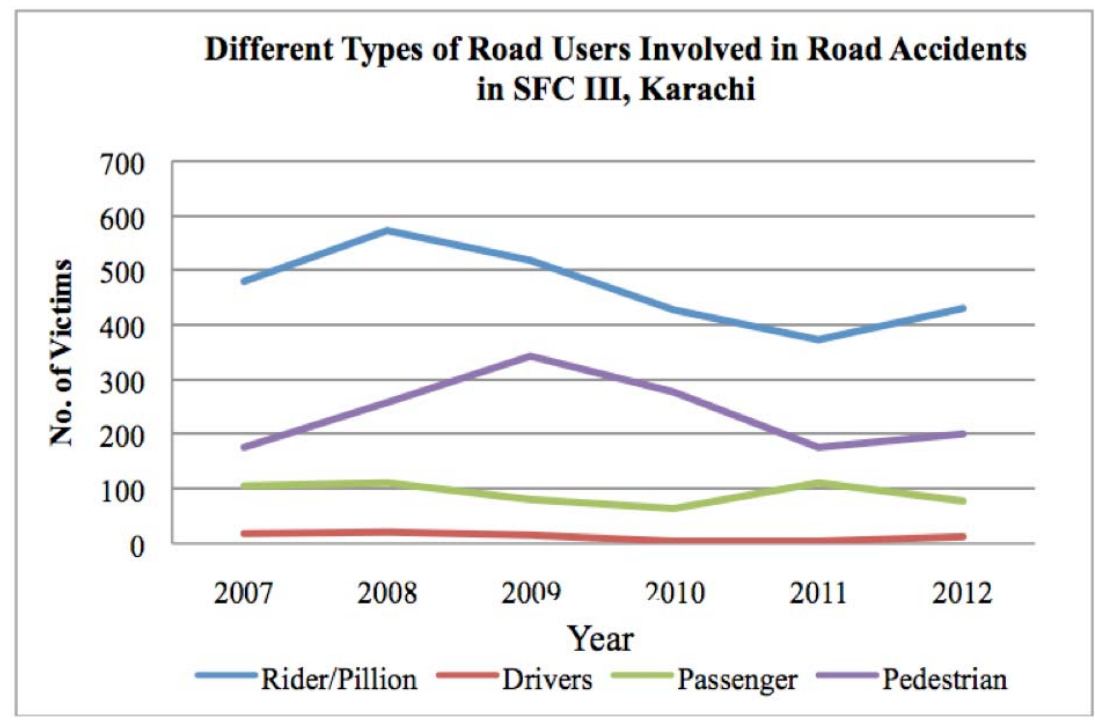

Figure 11: Types of Road users involved in Corridor III in Karachi.

minor injury victims were registered in the year 2011, amounting to 573. Severe injury victims also showed a declining trend from year 2008 with 241 victims and least number of such victims having been recorded in the year 2011 i.e. 162 only. However, fatal injury victims revealed an increasing trend from 14 to 50 and 45 in the year 2008, 2009 and 2011 respectively.

Riders and pedestrians were the most vulnerable road user groups in corridor III. Highest number of bike/pillion riders were involved in the year 2008 i.e. 573 victims. The least number of such victims were 373 noticed in the year 2011. Highest number of pedestrians were reported in the year 2009 i.e. 343 and the least number of pedestrian were reported in the year 2007 and 2011 i.e. 176 victims each year. The highest numbers of passengers were found in the year
2008 i.e. 111 and least number of passengers were involved in the year 2010 i.e. 64 only. Whereas, highest number of drivers involved in RTAs were in the year 2008 i.e. 21 and least number of drivers involved in RTAs were in 2010 i.e. 4 only.

\section{RTAs at Signal Free Corridor IV}

Although construction of this corridor is in progress and has not yet been completed, however it has been deemed essential in order to analyze the temporal change of RTA trend on the proposed artery, designated for signal free corridor IV.

In SFC IV, Minor Injury victims were highest in number i.e. 2139 in 2007, which revealed a declining trend with least number in the year 2009 i.e. 1379. 


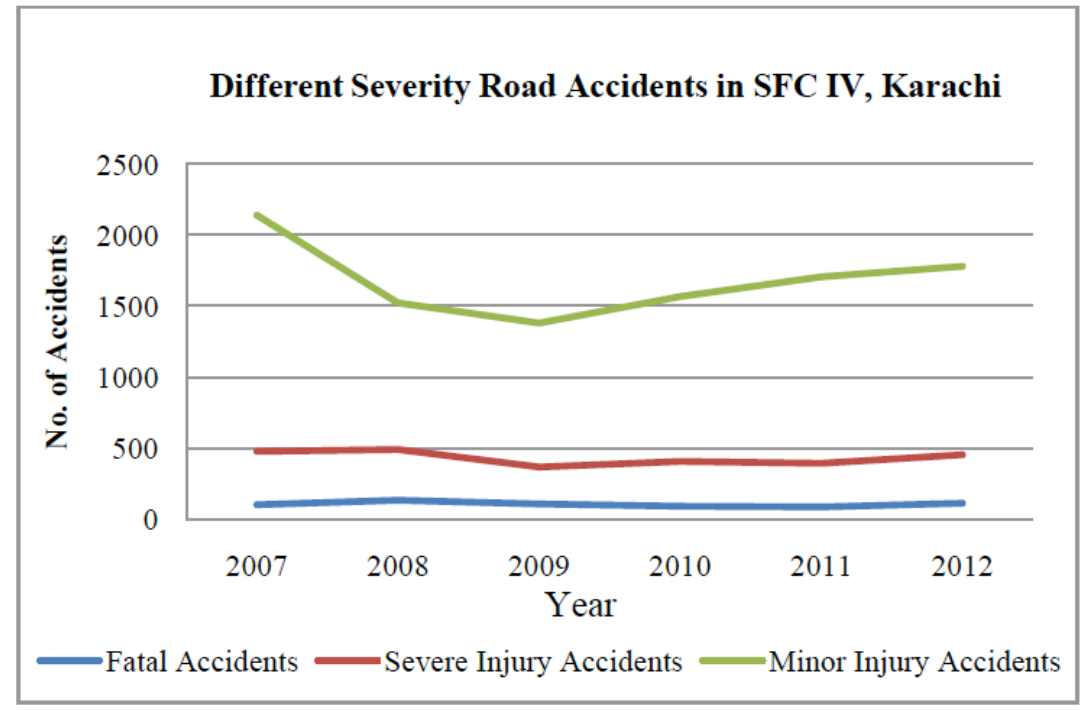

Figure 12: Types of Accidents in Corridor IV, Karachi.

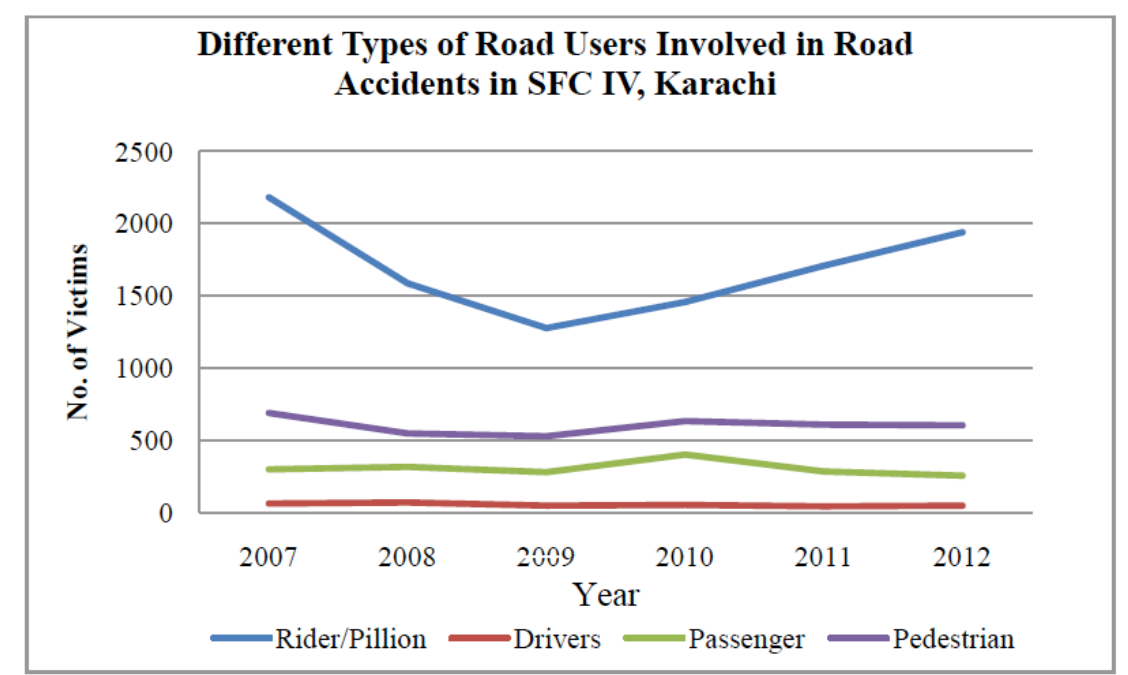

Figure 13: Types of Road users involved in Corridor IV in Karachi.

However, it once again showed an increasing trend in the year 2012 i.e. 1778. Highest number of severe injury victims were reported in the year 2008 i.e. 488 . Whereas, least number of same category victims were reported in the year 2009 i.e. 364 . Fatal injury victims showed a steady pattern of highest number in the year 2012 i.e. 111 and least number of victims were reported in 2011 amounting to 84 .

In SFC IV the highest numbers of victims were bike/pillion riders. Their highest numbers noticed in the year 2007amounted to 2,180 and the least number were noticed in the year 2009 i.e. 1,276. Highest number of Pedestrian were victimized in the year 2010 i.e. 401 . In the year 2012, least number of pedestrians was offended amounting to 299. The highest numbers of passengers involved in RTAs were 401 in 2010.
Furthermore, in 2012 least number of passengers i.e., 255 was registered. Drivers were considered as least vulnerable road users with highest number involved in the year 2008 i.e. 71 and the least number in the year 2011 i.e. 43.

\section{CONCLUSION}

The study has revealed that the SFCs are major runners of Traffic Flow in Karachi, connecting peripheral parts of the city with the core areas. Moreover, these four arteries are responsible for considerable number of road accidents in the city. Although these roads have revealed a declining trend with reference to minor injuries due to accidents, however, showing an increasing trend for the category of severe and fatal injury accidents. Aserious aspect of 
concern regarding these roads is that they have been found to mostly affect the poor people of the society including bike/pillion riders and pedestrians. It has been observed that speedy traffic without enough road side accessories are more risky to road users especially to the bike/pillion riders and pedestrians who comprise the greater proportion of RTA victims.

Signals on the roads provide breathing time to traffic which help to reduce the chances of traffic jam in core areas. Reduced vehicle speed curtails the chances of accidents, specifically severe and fatal road accidents because speed control can increase the reaction time that could result in reduction of intensity as well as aftermath of RTAs [13]. It is required to make necessary amendments in the current design of these roads and also provide ample road side accessories to ease the road users. This would enable reduction in the incidence of RTAs and an in control and less speedy traffic would result to less severe and fatal injury accidents.

\section{ACKNOWLEDGEMENT}

Authors would like to acknowledge Dr. Rashid Jooma (Head of RTIPC), Prof. Dr. Mir Shabbar (Chairman, Department of Urban Planning NED University) who provided the point data of road accidents of various years. Authors are also thankful to Mr. Muhammad Ahmed for handling the data and also the team members who collected the accident data.
[2]

Karlaftis MG, Golias I. Effects of road geometry and traffic volumes on rural roadway accident rates. Accident Analysis \& Prevention 2002; 34(3): 357-365. http://dx.doi.org/10.1016/S0001-4575(01)00033-1

[3] Iyinam A, lyinam S, Ergun M. Analysis of relationship between highway safety and road geometric design elements: Turkish case. Technical University of Istanbul, Faculty of Civil Engineering, Turkey 1997.

[4] Zubair S, Kazmi SJH. Spatial Framework for the Assessment of Road Traffic Accidents in Karachi. Journal of Basic and Applied Sciences 2013; 9: 525-532.

[5] Kazmi JH, Zubair S. Estimation of vehicle damage cost involved in road traffic accidents in Karachi, Pakistan: a geospatial perspective. Procedia Engineering 2014; 77: 7078. http://dx.doi.org/10.1016/j.proeng.2014.07.008

[6] Zubair S. 'Pakistan develops search engine for free online courses'. 2013 [cited 2013 October 08, 2013]; Available from: http://www.dawn.com/news/1048119/pakistan-developssearch-engine-for-free-online-courses.

[7] Zubair S, Shaikh MA. U-Turns and road safety-perspective from Karachi.

[8] Matin F, Herani GM, Warraich UA. Factors Affecting Traffic Jam in Karachi and its Impact on Performance of Economy. KASBIT Journal of Management \& Social Science 2012; 5: 25-32.

[9] Staff Reporter, D.N. KARACHI: Musharraf to inaugurate signal-free corridor today. 2007 [cited 2014 February 10th] Available from: http://www.dawn.com/2007/02/09/local3.htm.

[10] News, S.R.D. KARACHI: Rs3 billion signal-free corridor opened. 2008 [cited 2014 February 15th]; Available from: http://www.dawn.com/2008/10/10/local1.htm.

[11] (Sindh), G.G.o., Transport Policy. Government of Sindh: Karachi 2011.

[12] CDGK. I Own Karachi. 2013 [cited 2014 March 30th]; Available from: https://sites.google.com/site/ iownkarachisite/ system/ app/ pages/sitemap/hierarchy.

[13] JCSD, Transport Roads and Maritime Services. ACT Road Rules Handbook. Australian Capital Territory: CanberraAustralia 2014.

\section{REFERENCES}

[1] Kopits E, Cropper M. Traffic fatalities and economic growth. World Bank Policy Research Working Paper 2003; 3035.

http://dx.doi.org/10.6000/1927-5129.2015.11.35

(C) 2015 Zubair et al.; Licensee Lifescience Global.

This is an open access article licensed under the terms of the Creative Commons Attribution Non-Commercial License (http://creativecommons.org/licenses/by-nc/3.0/) which permits unrestricted, non-commercial use, distribution and reproduction in any medium, provided the work is properly cited. 